http://dx.doi.org/10.18675/1981-8106.vol25.n49.p390-395

\title{
Introdução à Sociologia
}

ELIAS, Norbert. Introdução à Sociologia. Tradução Maria Luísa Ribeiro Ferreira. Braga, Portugal: Editora Pax Limitada, 1980.

\author{
Renata Peres Barbosa' \\ 'Universidade Tecnológica Federal do Paraná, Londrina, Paraná - Brasil. E-mail: \\ re_pbarbosa@hotmail.com
}

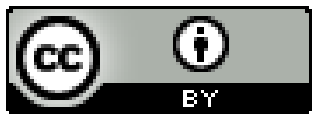

Educação: teoria e prática, Rio Claro, SP, Brasil - eISSN: 1981-8106

Está licenciada sob Licença Creative Common

Nascido na Polônia, Norbert Elias é um escritor que obteve reconhecimento de seu trabalho tardiamente. Autor de "O processo civilizador", "A sociedade de corte", "Os alemães", "Introdução à Sociologia”, entre outros, Elias propõe uma teoria sociológica para entender as relações sociais, que podemos denominar de teoria configuracional ou figuracional. Para compreender como as relações individuais e sociais foram se constituindo, busca analisar, em suas obras, a psicogênese e a sociogênese das relações. O presente estudo perspectiva esboçar uma resenha de "Introdução à Sociologia" - obra em que Elias promove um novo olhar acerca das questões sociológicas de nosso tempo. Nesta resenha, sintetizamos brevemente cada um dos seis capítulos da obra, no intuito de elucidar seus principais conceitos.

A obra intitulada "Introdução à Sociologia" é considerada tardia na carreira de Norbert Elias, publicada em 1970. Trata-se de uma continuação das obras anteriores, no entanto, com um novo viés crítico. Nessa obra, Elias teve como objetivo ressaltar a importância da necessidade de uma reorientação do discurso sociológico, ao considerar que estamos impregnados pela "necessidade causal, determinismo, leis científicas" (ELIAS, 1980, p.22), pela cientificação do pensamento. Com efeito, a defesa do autor, é que o papel da sociologia, frente tais premissas, é se voltar à compreensão das forças sociais, de modo que se afaste do modelo mítico e egocêntrico do conhecimento.

Ainda, no que concerne aos aspectos gerais da obra, o autor deteve-se na formulação de conceitos próprios das ciências sociais, das particularidades das representações sociais dos homens. Desse modo, salienta que a sociologia "deverá produzir gradualmente outros conceitos, que sejam mais adequados às particularidades das representações sociais do homem" (ELIAS, 1980, p.18). Na obra em questão, o autor faz o exercício de repensar temas fundamentais do discurso sociológico tais como indivíduo, grupo, relações de poder, interconexões sociais, conhecimento científico entre outros, em busca de novos instrumentos conceituais. 
Segundo o autor, para compreender a sociologia é preciso termos consciência de nós enquanto seres humanos entre outros seres humanos. Para ele, reificamos e desumanizamos as estruturas sociais, as consideramos além dos indivíduos - visão egocêntrica da sociedade. Isto é, têm-se as estruturas sociais como entidades extra-humanas - o que considera como modelos heterônomos de discursos da linguagem social e do pensamento. À vista disso, preza por uma compreensão mais sólida da dinâmica das Interconexões sociais, de modo a obter um novo olhar acerca da história da civilização. Nesse sentido, contempla-se a discussão a partir de uma visão da história e das diferenças de poder, partindo da premissa de que os padrões de interdependência são mutáveis. Destarte, a obra ultrapassa o conhecimento da sociologia, sendo uma síntese dos conhecimentos da história, da política, da psicologia e da sociologia.

À luz desse contexto, Elias parte do pressuposto de que a concepção filosófica de ciência que concebe o conhecimento como algo estático, mecânico, rompeu com qualquer tipo de investigação que envolvesse a sociogênese e a psicogênese do discurso científico. Isso a reduz a uma concepção acrítica e reducionista de ciência, sustentada, inicialmente, pelos modos de investigação no âmbito das ciências naturais. Tais discursos constituíram-se inadequados, impedindo o desenvolvimento da autonomia frente o pensamento. Logo, o pensamento deixou de ser problematizado, pensado.

O autor ainda sublinha a dificuldade que hoje se tem na compreensão dos assuntos sociais. De acordo com suas considerações, desde o período medieval, recorremos a explicações fantasiosas para suprir a angústia da ignorância. À título de ilustração, assinala o exemplo do Nacional Socialismo, em que se teve a ilusão de acabar com a miséria por meio da culpa das minorias. Trata-se de "explicações fantasiosas para a miséria social e para a ansiedade, cujas verdadeiras causas não podemos ou não queremos ver" (ELIAS, 1980, p.29), que mascaram os verdadeiros interesses.

O livro está dividido em seis capítulos. Consideramos importante apresentar as ideias centrais dispostas em cada um deles, sem pormenorizar. No primeiro capítulo, Elias inicia seus escritos com ênfase na trajetória de Auguste Comte, o pai da sociologia e fundador do positivismo filosófico. O autor se detém em aventar os corolários da proposta de Auguste Comte, em especial, no que concerne à evolução das estruturas do pensamento e das estruturas sociais. Dessa forma, Norbert Elias reconhece que Auguste Comte, na articulação do positivismo filosófico do século XVIII, marcou "o impulso significativo para o desenvolvimento da sociologia e para a filosofia da ciência" (ELIAS, 1980, p.40). Ainda nesse primeiro capítulo, para finalizar, o autor realiza o exame do processo social da evolução do pensamento e do conhecimento - do conhecimento não-científico para o conhecimento científico. Nesse momento, Elias se volta para o debate travado sobre as características específicas que poderiam definir e legitimar o método científico, o que distingue o pensamento científico do pré-científico. Por fim, ao conferir à sociologia o status de uma ciência relativamente autônoma, o autor deixa claro que seu objeto não poderia ser reduzido a estruturas biológicas e às leis da fisiologia.

No segundo capítulo, Elias se posiciona de maneira mais enfática. O autor defende o rompimento de duas grandes correntes teóricas, a saber: a teoria filosófica da ciência - que 
toma o conhecimento científico como certo, como verdade absoluta; e a teoria sociológica da ciência, que emergiu da obra de Comte. Nesse sentido, que é o eixo central do capítulo, critica a ideia de método ou instrumento conceitual independentemente do objeto a ser investigado, ou seja, critica a ideia de o objeto manter-se refém do método científico.

No mesmo capítulo, o autor ainda disserta acerca das relações de poder, e como, historicamente, essas relações de poder sofrem alterações, havendo novas roupagens, novas distribuições sociais, conforme o período histórico e os grupos sociais. Nesse sentido, ressalta que "as cadeias de interdependência alargam-se e tornam-se mais diferenciadas; tornam-se consequentemente mais opacas e mais incontroláveis" (ELIAS, 1980, p.73). O autor sintetiza, por fim, para concluir o capítulo, a relação entre o desenvolvimento das ciências sociais do desenvolvimento social global. Norbert Elias encerra com a seguinte problematização, lançando o próximo capítulo: em meio à complexidade das cadeias de interdependência, o que se tem tido primazia, é demarcado ou por indivíduos que ora se respaldam em explicações científicas, ora em explicações ideológicas, que são sistemas de crenças e ideais carregados de emotividade - ambos promovem uma satisfação imediata, embora ilusória.

No terceiro capítulo, Elias trata das questões relacionadas à teoria figuracional, importante conceito que busca tecer nessa obra. De acordo com o autor, para se compreender o comportamento, as ações dos indivíduos em determinadas sociedades, é preciso considerar as relações de interdependência entre os seres humanos, de como estas vão constituindo, se articulando, de como vão formando as configurações uns com os outros.

Para exemplificar as configurações dos seres humanos, e, com isso, pensar nas tarefas com as quais a sociologia se defronta, em especial, no que tange ao seu objeto de estudo, o autor analisa as relações de poder, ilustrando com a situação de jogos. Para ele, o caminho que o jogo irá tomar depende das ações dos indivíduos, devido à existência de uma relação de interdependência. Isto é, o jogo não tem uma dinâmica própria, independente dos indivíduos, pelo contrário, será guiado pelas ações dos jogadores e da relação uns com os outros. $\mathrm{O}$ conceito de configuração implica, portanto, nesse padrão mutável, nítido na dinâmica do jogo, no entrelaçamento das ações dos jogadores, interdependentes e mutáveis.

De acordo com o autor, as configurações não seguem necessariamente regras, não se tem o controle acerca do que irá acontecer. Sendo assim, pensar as sociedades sob a perspectiva de uma estrutura social segundo normas e regras, sem considerar a desordem, o que surge é uma visão distorcida das sociedades humanas. Para ele,

[...] é perfeitamente possível estruturar as relações sociais entre os indivíduos, mesmo que estas se desenrolem sem regras. Mesmo uma situação que aparece às pessoas nela envolvidas como o cúmulo da desordem faz parte de uma ordem social. Não há qualquer razão para que as 'desordens' históricas - guerras, revoluções, rebeliões, massacres e toda a espécie de lutas pelo poder - não possam ser explicadas. Fazê-lo, é na verdade uma das tarefas da sociologia (ELIAS, 1980, p. 82). 
Em linhas gerais, o terceiro capítulo convida à discussão acerca do papel da sociologia, enquanto instrumento de compreensão das configurações sociais, considerando a mutabilidade das relações de interdependência e de poder, o que difere da visão científica presente na modernidade. Em outras palavras, "a sociologia trata de pessoas; as interdependências que ocorrem entre elas são o seu problema central" (ELIAS, 1980, p.109).

No quarto capítulo, Elias irá discorrer sobre o processo de mudança evolutiva dos seres humanos e, consequentemente, da mudança do padrão de vida social - busca escapar do sentido positivista do termo - no qual torna saliente a mutabilidade enquanto forte característica dos seres humanos. Utiliza, como exemplo, o discurso de Tacott Parson, em que este considera a mutabilidade apenas enquanto uma perturbação em meio ao equilíbrio do sistema social. Elias se contrapõe a essa concepção, explicitando a mutabilidade enquanto característica vital, inerente aos seres humanos e à vida social. Tal defesa, significa considerar a mudança, o movimento, contrário ao olhar estático e mecânico enfatizado nos processos científicos tradicionais. Para o autor, a sociologia exige esse olhar dinâmico, sem medo do caos, pois somente assim compreenderemos, de fato, os processos sociais. Conforme suas palavras:

\begin{abstract}
Flutuamos, por assim dizer, entre o considerarmos o estado de repouso como sendo algo normal e o movimento como um caso especial. Chegaremos a uma melhor compreensão das matérias-primas com que lida a sociologia, se não nos abstrairmos do seu movimento e do seu caracter processual e usarmos conceitos que captem a natureza processual das sociedades em todos os seus diferentes aspectos, como uma estrutura de referência para a investigação em qualquer situação social dada (ELIAS, 1980, p. 126).
\end{abstract}

Fica evidenciado, nesse capítulo, o conceito de configuração, já frisado em outros momentos do texto. Elias enfatiza a interdependência e a mutabilidade das relações, o caráter dinâmico e processual das relações dos seres humanos que formam as configurações que estão continuamente em fluxo. Nesses termos, "o conceito de configuração serve, portanto, de simples instrumento conceptual que tem em vista afrouxar o constrangimento social de falarmos e pensarmos como se o 'indivíduo' e a 'sociedade' fossem antagônicos e diferentes" (ELIAS, 1980, p.141).

No quinto capítulo, o autor ilustra as diversas relações de interdependência, indicando que a dependência entre as pessoas não é sempre a mesma. Assim, aborda situações em que as dependências são de cunho afetivo, político, econômico, entre outros. Ainda nesse capítulo, lança a discussão acerca da evolução do conceito de desenvolvimento e as interdependências que este carrega.

Para finalizar sua obra, no sexto e último capítulo, Elias discorre sobre a teoria da evolução social. A pergunta que move a discussão desse capítulo é: os processos de evolução são inevitáveis? Segundo Elias, a filosofia da ciência fortalece a ideia de que se uma tendência no passado foi evolutiva, ela continuará evoluindo no futuro, de maneira 
automática. Contrariamente a essa concepção, o autor salienta que "cada movimento deverá ser explicado por outro movimento e não por uma primeira causa” (p.178). À vista disso,

É sempre possível estabelecer que a configuração B tinha de ser precedida de uma determinada configuração $\mathrm{A}$, embora não se possa afirmar com a mesma certeza que a configuração A leve inevitavelmente à configuração B. As forças compulsivas deste segundo tipo não são desconhecidas no seu conjunto. Contudo, aplicar-lhes o conceito de inevitabilidade é arriscarmonos a ficar envolvidos na selva das associações físicas e metafísicas, que mesmo hoje são evocadas sempre que se menciona a inevitabilidade em relação a uma evolução social progressiva (ELIAS, 1980, p.178).

Nesse sentido, transparece, nesse capítulo, a necessidade de se considerar a dinâmica nas relações, e superar as relações causais e mecânicas presentes no discurso científico. Para ele, para se pensar a sociedade é preciso ir além do que se tem no habitual, no discurso determinista, e, ao mesmo tempo, não cair no outro extremo, no discurso indeterminista, pois ambos desconsideram as relações de interdependências entre os indivíduos. Isso se explica na medida em que "as configurações não têm de modo algum a mesma capacidade de mudança" (ELIAS, 1980, p.180).

A partir das considerações tecidas em "Introdução à sociologia", podemos concluir que Norbert Elias, de modo eloquente, ressalta que estamos agindo conforme um padrão, um controle social, e esse padrão de conduta têm como respaldo um ethos que não é explícito, não é planejado, nem previsível. Dentre os méritos desse livro, cumpre destacar o esforço que o autor utiliza no decorrer de sua obra, intentando enfatizar a importância do leitor se ater, de obter um novo olhar acerca das questões sociológicas de nosso tempo. Como ponto central dessa obra, bem como das outras obras do autor, surge o conceito de figuração. Esse conceito permite compreendermos a concepção de Elias acerca das relações de interdependência entre os seres humanos, do caráter dinâmico e processual das relações, do fluxo contínuo de se viver em sociedade. É possível verificar, no decorrer de seus escritos, a busca por uma nova justificação da sociologia, e, consequentemente, um novo modo de encarar os problemas da sociedade.

É possível dar relevo à grande contribuição dessa obra para se pensar em problemas contemporâneos. Vê-se, muitas vezes, as relações do conhecimento se sedimentarem à luz da cientificação do pensamento, pautadas no imediatismo, em conclusões que não contemplam o verdadeiro refletir, não possuem instrumentos conceituais adequados para tal compreensão. A obra de Elias critica a teoria do conhecimento enquanto estático e mecânico, e esse, talvez, seja o problema principal da obra do autor. Em suma, para Elias, ainda falta uma compreensão mais sólida da dinâmica das interconexões sociais, e é o que o autor busca tratar no decorrer de toda sua obra.

Recebido em: 02/12/2014 
Aprovado para publicação em: 23/04/2015

Publicado em: 31/08/2015 